Nerve Conduction Findings in Median and Ulnar Nerves

\begin{tabular}{|c|c|c|c|c|c|}
\hline & $\begin{array}{l}\text { Term. } \\
\text { latency/ } \\
\text { finger- } \\
\text { wrist } \\
\text { (msec/ } \\
{[\mathrm{m} / \mathrm{sec}] \text { ) }}\end{array}$ & $\begin{array}{l}\text { Forearm } \\
(\mathrm{m} / \mathrm{sec})\end{array}$ & $\begin{array}{l}\text { Elbow } \\
(\mathrm{m} / \\
\mathrm{sec})\end{array}$ & $\begin{array}{l}\text { Upper } \\
\text { arm } \\
(\mathrm{m} / \mathrm{sec})\end{array}$ & $\begin{array}{l}\text { F- } \\
\text { wave } \\
\text { (msec) }\end{array}$ \\
\hline \multicolumn{6}{|c|}{ Motor nerve conduction } \\
\hline Median & $4.4(15)^{\mathrm{a}}$ & 51 & & 53.0 & 30.5 \\
\hline Ulnar & $3.0(13)$ & 52.4 & 29.4 & $\overline{54.1}$ & $\overline{28.8}$ \\
\hline \multicolumn{6}{|c|}{ Sensory and mixed nerve conduction (ortbodromic) } \\
\hline Median & $32.4(15)^{\mathrm{a}}$ & $51(20)$ & & $54.1(20)$ & \\
\hline Ulnar & $30.0(10)$ & $42.3(10)$ & & $44.8(18)$ & \\
\hline
\end{tabular}

${ }^{a}$ Underlined numbers represent abnormal values; numbers in parentheses indicate the amplitude of CMAP $(\mathrm{mV})$ or CNAP $(\mu \mathrm{V})$.

\section{Causes of Stroke}

\section{William M. Landau, MD}

The abstract of the paper "Etiology of Motor or Sensory Stroke"[1] follows the text in declaring that "the causes of ischemic stroke in the other 81 patients were penetrating artery disease ( 32 patients), large artery occlusive disease (17), cardioembolism (12), other causes (8), and undetermined (12)." No clinical/pathological correlation is offered for any of the cases in this series. The authors presume that any cardiac abnormality establishes the cardiac cause of a small cerebral infarction. With no better evidence, small deep lesions not associated with the cardiac disease process are held to be caused by penetrating artery disease, unless they are larger than $2 \mathrm{~cm}$ when they become "stroke of undetermined cause."

The dictionary definition of cause is "something that brings about an effect or result." I believe that this should be a sacred word in scientific writing, not an ought-to-be or mightbe relationship. Terms such as "phenomenon," "correlated finding," "risk factor," and "possible cause" are not equivalent. There is ample evidence [2-5] that small holes in the brain may derive from more than one mechanism.

The authors' last page confession that "recognition of a vascular lesion does not constitute proof that the lesion caused the patient's stroke" seems to deny their own conclusion. If we are ever to learn anything about the pathogenesis of cerebrovascular disease, I believe that both authors and editors will have to insist upon phenomenological and logical criteria equivalent to Koch's postulates for infectious disease [6].

\section{Department of Neurology and Neurological Surgery (Neurology) Washington University School of Medicine St Louis, MO}

\section{References}

1. Chimowitz MI, Furlan AJ, Sila CA, et al. Etiology of motor or sensory stroke: a prospective study of the predictive value of clinical and radiological features. Ann Neurol 1991;30:519-525
2. Sacco SE, Whisnant JP, Broderick JP, et al. Epidemiological characteristics of lacunar infarcts in a population. Stroke 1991;22: $1236-1241$

3. Cacciatore A, Russo LS Jr. Lacunar infarction as an embolic complication of cardiac and arch angiography. Stroke 1991;22:16031605

4. Zhu CZ, Norris JW. Lacunar infarction and carotid stenosis. Ann Neurol 1991;30:244

5. Millikan C, Futrell N. The fallacy of the lacune hypothesis. Stroke 1990;21:1251-1257

6. Susser M. What is a cause and how do we know one? A grammar for pragmatic epidemiology. Am J Epidemiol 1991;133:635-648

\section{Reply}

Marc I. Chimowitz, MD, ${ }^{*}$ and Anthony J. Furlan, MD†

One of the major responsibilities of clinicians, when faced with patients with cerebrovascular disease, is to identify vascular lesions for which specific stroke preventive therapy can be instituted, e.g., carotid endarterectomy for symptomatic high-grade carotid stenosis, and anticoagulation for cardiac lesions that predispose to embolism.

Fisher $\{1,2\}$ has suggested that, in patients presenting with pure sensory stroke or pure motor hemiparesis, it is unnecessary to search for carotid stenosis or a cardiac lesion because these syndromes are invariably caused by penetrating artery disease. Other authors strongly disagree [3, 4]. We tested Fisher's hypothesis by performing brain computed tomography or magnetic resonance imaging, echocardiography, and cerebrovascular imaging in consecutive patients with motor or sensory stroke [5]. Diagnostic classification was based on the results of these in vivo studies. Nonetheless, we failed to satisfy Dr Landau's penchant for diagnostic precision ultimately, it seems, because we were forced to deal with living patients.

In our study, if a patient did not have a well-established cardiac source of embolism (not any cardiac abnormality as Dr Landau suggests), proximal large artery occlusive disease (>50\% stenosis), or another identifiable cause for a small $(<2 \mathrm{~cm})$ subcortical infarct, we attributed the cause of stroke to penetrating artery disease. For readers, like Dr Landau, who find the label "penetrating artery disease" objectionable because of the lack of pathological data, we suggest a descriptive term such as "small subcortical stroke that is not associated with a cardioembolic source, proximal large artery occlusive disease, or other identifiable cause."

We found that pure sensory stroke and pure motor hemiparesis $(F=A=L)$ associated with subcortical infarction less than $1.5 \mathrm{~cm}$ were predictive of penetrating artery disease (or, if the readers prefer, the absence of another potential cause) in over $90 \%$ of cases. These results do not refute the obvious fact that "small holes in the brain may derive from more than one mechanism," but they strongly support Fisher's original hypothesis that causes other than penetrating artery disease are unusual. The clinical implication of these findings is that invasive and expensive procedures such as cerebral angiography and echocardiography are not warranted in patients with these syndromes.

Our "confession" that some of the strokes that we attributed to 50 to $60 \%$ carotid stenosis or a cardioembolic source may actually have been caused by penetrating artery disease 
strengthens rather than weakens our conclusions because the design of the study was biased (intentionally) toward attributing the cause of stroke in these patients to cardioembolic or large artery occlusive mechanisms.

Dr Landau correctly asserts that we have not proven that penetrating artery disease per se causes the small, deep infarcts as defined. Logic dictates, however, that until we can image arteriolar wall pathology in vivo, circumstantial evidence such as ours is more useful clinically than quixotic ruminations on Koch's postulates for stroke.

\section{*Department of Neurology University of Michigan Medical Center, Ann Arbor, $M I$ \\ tDepartment of Neurology \\ The Cleveland Clinic, Cleveland, $\mathrm{OH}$}

\section{References}

1. Fisher CM, Curry HB. Pure motor hemiplegia of vascular origin. Arch Neurol 1965;13:30-44

2. Fisher CM. Pure sensory stroke involving face, arm and leg. Neurology 1965;15:76-80

3. Landau WM. Au clair de lacune: holy, wholly, holey logic. Neurology 1989;39:725-730

4. Millikan C, Futrell N. The fallacy of the lacune hypothesis. Stroke 1990;21:1251-1257

5. Chimowitz MI, Furlan AJ, Sila CA, et al. Etiology of motor or sensory stroke: a prospective study of the predictive value of clinical and radiological features. Ann Neurol 1991;30:519-525

\section{Collapsing Borders?}

James Perry, MD

In the face of widespread political and territorial change in our world, it is interesting to examine the meeting notices in recent issues of the Annals. Listed under "meetings outside North America" have been no less than four events being held in Canada, including the American Neurological Association annual meeting.

Is this a reflection of world change, pro-Americanism, or just bad geography? Unfortunately, according to my Chairman, this new interpretation of continental boundaries does not qualify me for foreign travel grants to Montreal or Winnipeg.

\section{University of Toronto}

Toronto, Ontario, Canada

\section{Reply}

A. K. Asbury, MD

Dr Perry is correct. Annals has erred. Borders have not collapsed, but our alertness has. May our colleagues in Canada be moved to forgiveness.

Editor, Annals of Neurology

\section{Mitochondrial DNA Mutation and Leigh's Syndrome}

Ryoichi Sakuta, MD, ${ }^{*}$ Yu-ichi Goto, MD,* Satoshi Horai, MD, $\uparrow$ Tatsuya Ogino, MD, $\ddagger$ Harumi Yoshinaga, MD $\ddagger$ Shunsuke Ohtahara, MD, and Ikuya Nonaka, MD*

Leigh's syndrome, a progressive neurodegenerative disorder with preferential involvement of the basal ganglia, is a group of heterogeneous metabolic disorders that includes deficiencies in pyruvate dehydrogenase complex (PDHC), cytochrome $c$ oxidase (COX), and NADH-coenzyme $\mathrm{Q}$ reductase. In this communication we describe a patient with Leigh's syndrome with a maternally transmitted mitochondrial (mt) DNA mutation.

After Tatuch and coworkers [1] reported mtDNA mutation from $T$ to $G$ at position 8993 within the ATPase 6 gene in a female infant with Leigh's syndrome and her mother, we examined mtDNA in muscle biopsy specimens from 23 patients with the clinical characteristics of Leigh's syndrome to determine whether this mutation is a common abnormality in this disorder. Among our patients, one had NADHcoenzyme $Q$ reductase deficiency, whereas 6 had COX deficiency and 16 had no identifiable enzyme defect.

mtDNA in the region from positions 8838 to 9017 within the ATPase 6 gene was amplified by polymerase chain reaction and digested with the restriction enzyme HpaII. Since the 8993 mutation created a HpaII recognition site (CCTG to CCGG), the 179-base PCR products harboring the mutation were cleaved into 155 - and 24-base fragments. With this procedure, we detected the mutation in 1 of 23 patients in heteroplasmic fashion. In a previous study on mtDNA restriction analysis, there was no recognition site of $\mathrm{HpaII}$ at position 8993 in 116 normal Japanese subjects [2].

A 7-year-old girl with this mutation had hypotonia, psychomotor regression, akinetic mutism, choreoathetosis, and respiratory abnormalities since early infancy with lactic acidosis and symmetrical low-density areas in the basal ganglia on computed tomography scan. No ragged-red fibers were seen in her muscle biopsy but COX activity was diffusely decreased. Except for mildly decreased COX activity, no biochemical defects were found. An identical mutation was found in her blood sample as well as in her mother's, suggesting a maternal inheritance (Fig). The ratio of mutant mtDNA calculated densitometrically on PCR products was $56.6 \%$ in the patient's blood cells and $4.8 \%$ in her mother's.

mtDNA mutation at position 8993 in heteroplasmic distribution has also been described in 4 members of a family who had a variable combination of developmental delay, retinitis pigmentosa, dementia, seizures, ataxia, proximal neurogenic muscle weakness, and sensory neuropathy [3]. It would appear, therefore, that this mutation is probably responsible for some neurological disorders with a maternal inheritance pattern, including Leigh's syndrome.

This point mutation leads to an amino acid change from a highly conserved leucine to arginine in ATPase subunit 6, thus probably causing failure in ATP synthesis. Because the 